\title{
Vitexin compound 1, a novel extraction from a Chinese herb, suppresses melanoma cell growth through DNA damage by increasing ROS levels
}

Nian Liu ${ }^{1,2+}$, Kuan Song Wang ${ }^{3,4+}$, Min Qi ${ }^{5}$, Ying Jun Zhou ${ }^{6}$, Guang Yao Zeng ${ }^{6}$, Juan Tao ${ }^{7}$, Jian Da Zhou ${ }^{8}$, Jiang Lin Zhang ${ }^{1,2^{*}}$, Xiang Chen ${ }^{1,2^{*}}$ and Cong Peng ${ }^{1,2^{*}}$

\begin{abstract}
Background: Vitex negundo $L$ (Verbenaceae) is an aromatic shrub that is abundant in Asian countries. A series of compounds from Vitex negundo have been used in traditional Chinese medicine for the treatment of various diseases. Cutaneous melanoma is one of the most aggressive malignancies. A significant feature of melanoma is its resistance to traditional chemotherapy and radiotherapy; therefore, there is an urgent need to develop novel treatments for melanoma.

Methods: We first examined the effects of VB1 (vitexin compound 1) on cell viability by CCK-8 (cell counting kit) and Colony Formation Assay; And then, we analyzed the apoptosis and cell cycle by flow cytometry, verified apoptosis by Immunoblotting. The in vivo effect of VB1 was evaluated in xenograft mouse model. Potential mechanisms of VB1's antitumor effects were explored by RNA sequencing and the key differential expression genes were validated by real-time quantitative PCR. Finally, the intracellular reactive oxygen species (ROS) level was detected by flow cytometry, and the DNA damage was revealed by Immunofluorescence and Immunoblotting.

Results: In this study, we show that VB1, which is a compound purified from the seed of the Chinese herb Vitex negundo, blocks melanoma cells growth in vitro and in vivo, arrests the cell cycle in G2/M phase and induces apoptosis in melanoma cell lines, whereas the effects are not significantly observed in normal cells. To study the details of VB1, we analyzed the alteration of gene expression profiles after treatment with VB1 in melanoma cells. The findings showed that VB1 can affect various pathways, including p53, apoptosis and the cell cycle pathway, in a variety of melanoma cell lines. Furthermore, we confirmed that VB1 restored the P53 pathway protein level, and then we demonstrated that VB1 significantly induced the accumulation of ROS, which resulted in DNA damage in melanoma cell lines. Interestingly, our results showed that VB1 also increased the ROS levels in BRAFi (BRAF inhibitor)-resistant melanoma cells, leading to DNA cytotoxicity, which caused G2/M phase arrest and apoptosis.
\end{abstract}

Conclusions: Taken together, our findings indicate that vitexin compound 1 might be a promising therapeutic Chinese medicine for melanoma treatment regardless of BRAFi resistance.

Keywords: Vitexin compound 1, Melanoma, ROS, DNA damage

\footnotetext{
*Correspondence: leozj|1010@126.com; chenxiangck@gmail.com; pengcongxy@csu.edu.cn

${ }^{\dagger}$ Nian Liu and Kuan Song Wang contributed equally to this work.

'Department of Dermatology, Xiangya Hospital, Central South University,

Changsha, Hunan, China

Full list of author information is available at the end of the article
}

(c) The Author(s). 2018 Open Access This article is distributed under the terms of the Creative Commons Attribution 4.0 International License (http://creativecommons.org/licenses/by/4.0/), which permits unrestricted use, distribution, and reproduction in any medium, provided you give appropriate credit to the original author(s) and the source, provide a link to the Creative Commons license, and indicate if changes were made. The Creative Commons Public Domain Dedication waiver (http://creativecommons.org/publicdomain/zero/1.0/) applies to the data made available in this article, unless otherwise stated. 


\section{Background}

Melanoma is a malignant tumor with a progressively increasing incidence and a poor prognosis around the world [1]. Cutaneous melanoma is the most common subtype of melanoma; it accounts for more than $90 \%$ of melanomas [2,3] and exhibits poor response to both traditional chemotherapy and radiotherapy [4]. Recently, based on understanding the details of this disease, breakthroughs have been made in the treatment of advanced melanoma [5]. Key genomic mutation genes, including BRAF (35-60\%) and NRAS (15-20\%), have been identified, which has led to the development of targeted therapeutic treatments for advanced melanoma [6, 7]. Targeted inhibitors such as vemurafenib (BRAF inhibitors, BRAFi), trametinib (MEK inhibitor, MEKi) and the combination of BRAFi+MEKi have been approved by the FDA for advanced melanoma patients carrying the V600E residue of the BRAF protein [8]. BRAF inhibitors, alone and in combination with MEK inhibitors, significantly reduce the tumor burden and improve the progression-free survival and response rates among advanced melanoma patients. However, the benefits of BRAFi monotherapy are only temporary; after $6 \sim 7$ months, most patients receiving monotherapy develop drug resistance $[9,10]$. Although the FDA has also approved several immunotherapies for advanced melanoma patients [11], the response rates are generally lower, and the severe side effects of immunotherapy are fatal for patients [12]. Therefore, there is an urgent need to develop novel drugs with low toxicity for the treatment of melanoma patients.

Vitex negundo L (Verbenaceae) is an aromatic shrub that is abundant in Asian countries [13]. Recently, a series of compounds from Vitex negundo have been used in traditional Chinese medicine for the treatment of various diseases [14-17]. For example, the compounds vitexin and isovitexin extracted from Vitex negundo were demonstrated to prevent myocardial ischemia-reperfusion injury and to exhibit anti-inflammatory or antioxidant properties [18]. EVn-50, which is another mixture of compounds from Vitex negundo seeds, shows broad antitumor activity for colon cancer, breast cancer, ovarian cancer, pancreatic cancer and breast cancer [14]. Purified VB1 is the most abundant vitexin compound in the EVn-50 mixture, and it has been found to inhibit growth and angiogenesis through suppression of the AKT/ FOXO3 pathway in hepatocellular carcinoma [19], to suppress the growth of choriocarcinoma by inhibiting mTOR signaling [20] and to exert a broad-spectrum cytotoxic effect by arresting cancer cells at G2/M phase cell cycle in many cancers [21]. However, no studies have addressed the effects of VB1 on melanoma. In addition, there is no comprehensive explanation of the molecular mechanism of VB1.
In this study, we found that VB1, which is the most abundant vitexin compound in the EVn-50 mixture of compounds, inhibits the growth of melanoma cells in vitro and in vivo by inducing DNA damage by regulating ROS accumulation. Interestingly, VB1 also blocks the growth of BRAFi-resistant melanoma cells regardless of resistance, which indicates that VB1 is a promising medicine for melanoma treatment.

\section{Methods \\ Chemical}

VB1 (vitexin compound-1, 6-hydroxy-4-(4-hydroxy-3methoxyphenyl)-3-hydroxymethyl-7-methoxy-3,4-dihydro -2-naphthaldehyde), which is a compound purified from the seed of the Chinese herb Vitex negundo, was extracted and isolated by our team member from the College of Pharmacy of Central South University (Changsha, China) (Fig. 1a). A VB1 stock solution was prepared by dissolving the compound in dimethyl sulfoxide (DMSO) and diluting it with pure water to a concentration of $2.5 \mathrm{mmol} / \mathrm{L}$. The VB1 was packed and stored at $4{ }^{\circ} \mathrm{C}$. The final concentration of DMSO in each sample was less than $0.02 \%$ ( $\mathrm{vol} / \mathrm{vol}$ ).

\section{Cell lines and culture}

Human malignant melanoma cell lines A375, Sk-Mel-5 and Sk-Mel-28 (American Type Culture Collection, USA) and vemurafenib-resistant A375(called RA) was generated as described in previous study [22]), were used in this study. The cells were grown in Dulbecco's modified Eagle's medium (BI, Israel) supplemented with 10\% fetal bovine serum (BI, Israel) at $37{ }^{\circ} \mathrm{C}$ and $5 \% \mathrm{CO}_{2}$. The RA cell line was used for drug resistance at 2 micro-moles per milliliter of vemurafenib, and the drug was removed one week before use.

\section{Cytotoxicity assay (CCK-8)}

Cells were seeded into 96-well plates $\left(2 \times 10^{3}\right.$ cells per well) to allow attachment and incubated overnight at $37{ }^{\circ} \mathrm{C}$ in media containing $10 \%$ FBS. This was followed by exposure to various concentrations of VB1 or DMSO (control) for 24, 48 and $72 \mathrm{~h}$. The cell viability (\%) was determined by CCK-8 assay (Selleck, USA) according to the manufacturer's instructions. The fluorescence of each plate was measured using a spectrophotometer at an emission of $450 \mathrm{~nm}$ (Beckman, USA). Each sample had 6 replicates. The cells in the control group were treated with equal amounts of DMSO. The half-maximal inhibitory concentration (IC50) values were calculated for $48 \mathrm{~h}$ using the GraphPad Prism software.

\section{Colony formation assay}

Cells were seeded into 6-well plates $\left(1-1.5 \times 10^{3}\right.$ cells per well) to allow attachment and incubated overnight at 

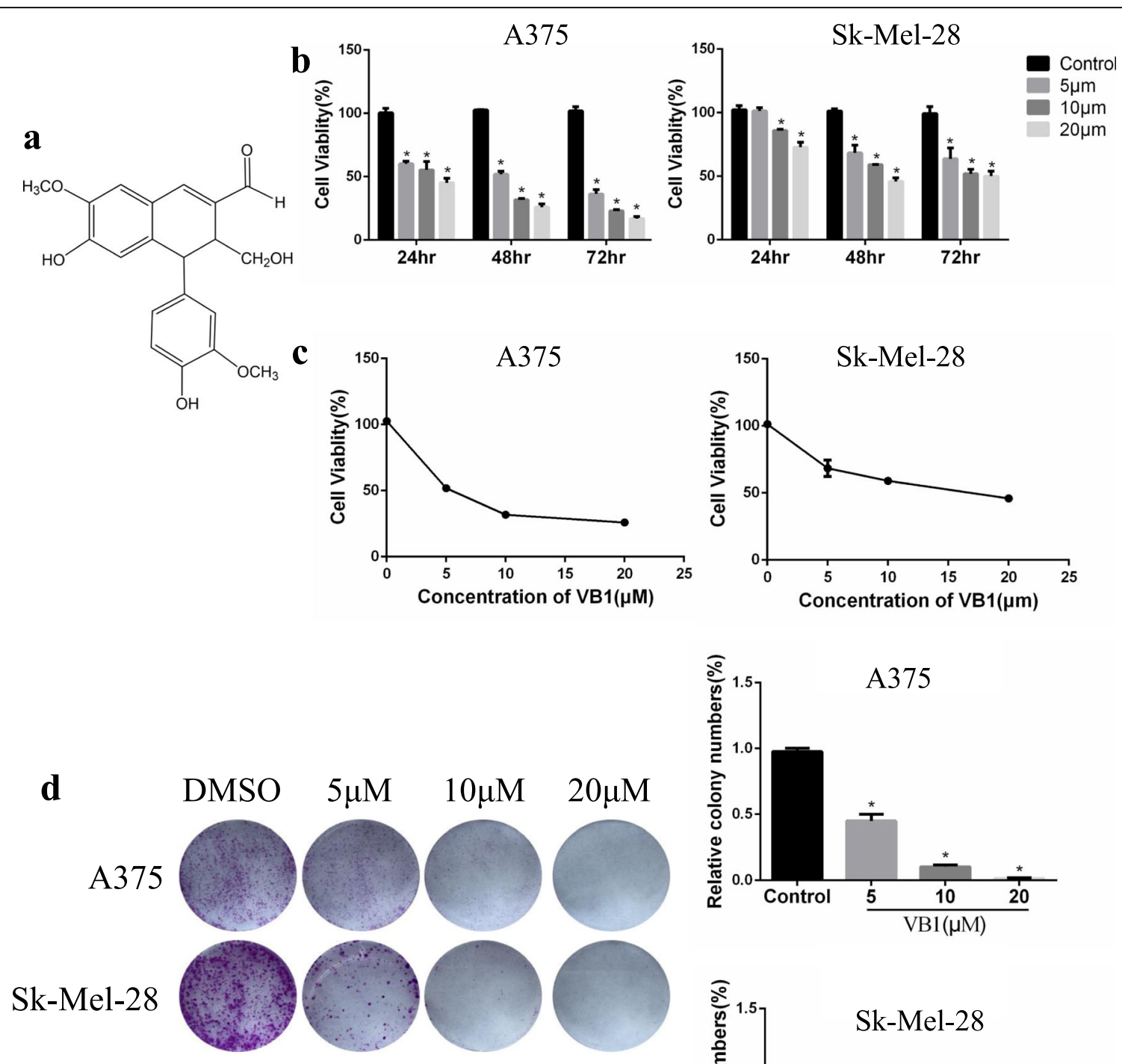

$\mathbf{e}$
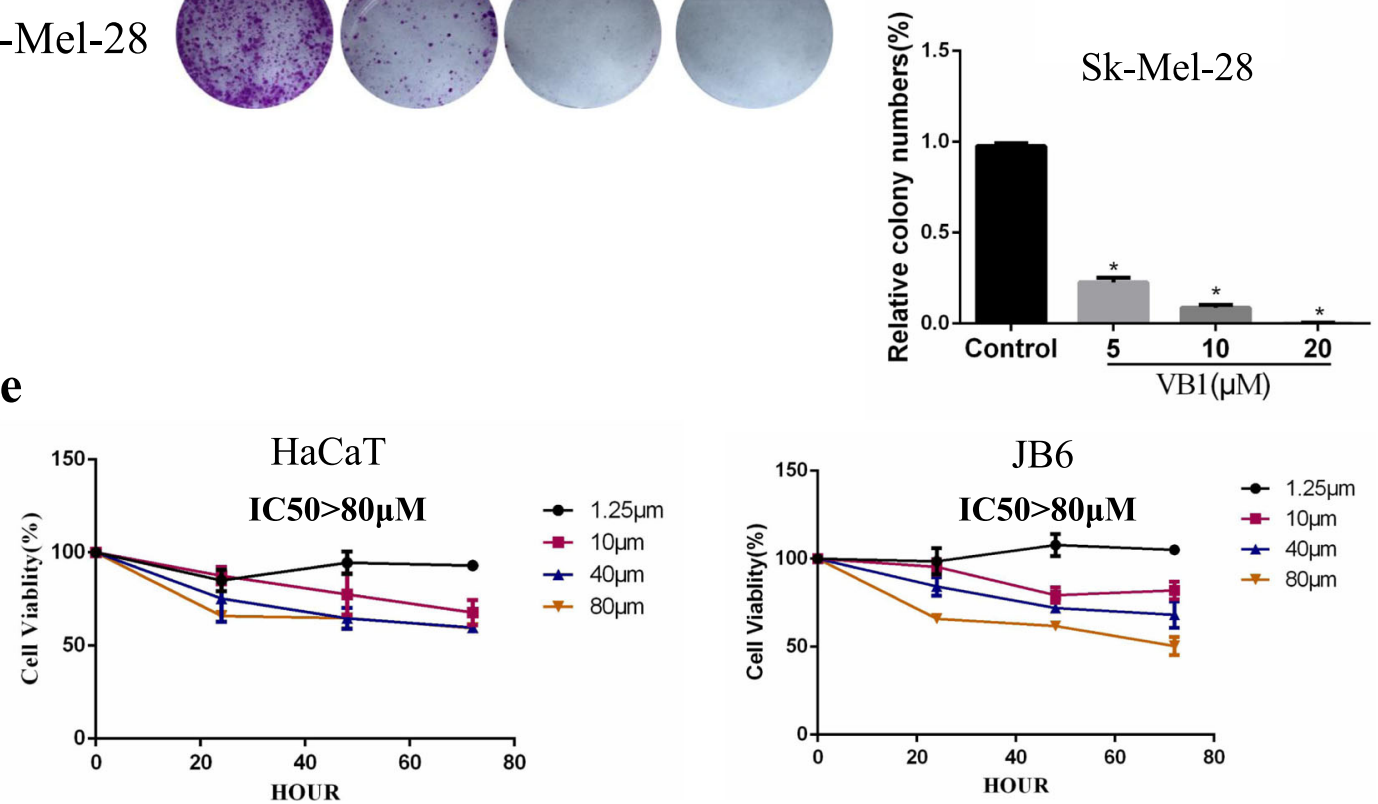

Fig. 1 (See legend on next page.) 


\begin{abstract}
(See figure on previous page.)
Fig. 1 VB1 blocks the proliferation of melanoma cells. a Chemical structure of VB1. b A375 and Sk-Mel-28 cells were prepared in 96-well plates. The cells were treated with VB1 for various times and dosages as indicated, and cell viability was tested by CCK-8 as described in the Methods. The data from multiple experiments are expressed as the mean $(n=6) \pm$ S.D. Significant differences were evaluated using one-way ANOVA, and an asterisk (*) indicates a significant difference $(p<0.05)$. c The IC50 values of VB1 in A375 and Sk-Mel-28 were automatically calculated by GraphPad Prism software as described in the Materials and Methods. d A375 and Sk-Mel-28 cells were seeded into 6-well plates, and then treated with various dosages of VB1 as indicated for $24 \mathrm{~h}$. After 10-14 days, the number of colonies was assessed and quantified by crystal violet staining as described in the Methods. The data represent the mean $(n=4) \pm$ SD of each group, and an asterisk $\left(^{*}\right)$ indicates a significant difference evaluated using one-way ANOVA $(p<0.05)$. e Nontumorigenic HaCaT and JB6 cells were treated with VB1 for different times and dosages as indicated. Cell viability was determined by the CCK-8 assay. The data from multiple experiments are expressed as the mean $(n=6) \pm$ S.D. Significant differences were evaluated using one-way ANOVA, and an asterisk (*) indicates a significant difference $(p<0.05)$
\end{abstract}

$37^{\circ} \mathrm{C}$ in media containing $10 \%$ FBS followed by exposure to various concentrations of VB1 or DMSO (control). After $24 \mathrm{~h}$, the drug-containing medium was removed and replaced with complete growth medium. The medium was then replaced every 3 days for 14 days until visible colonies formed. The colonies were simultaneously fixed with $4 \%$ paraformaldehyde and stained with $0.5 \%$ crystal violet. The dishes were washed with PBS. Visible colonies containing no less than 50 cells were counted.

\section{Cell apoptosis and cell cycle assay}

Cells were seeded into 6 -well plates $\left(3 \times 10^{5}\right.$ cells per well) to allow attachment, incubated overnight at $37{ }^{\circ} \mathrm{C}$ in media containing $10 \% \mathrm{FBS}$ and treated with various concentrations of VB1 or DMSO (control). For the cell cycle assays, the cells were harvested by trypsinization after $48 \mathrm{~h}$. The collected cells were washed with cold PBS and then fixed overnight in ice-cold $70 \%$ ethanol. The next day, the collected cells were incubated with propidium iodide (PI) staining (Becton, Dickinson and Company, USA) in the dark at room temperature according to the manufacturer's instructions. The cell cycle was measured by flow cytometry and analyzed using ModFit software. For the cell apoptosis assays, the cells were harvested by trypsinization without EDTA after $48 \mathrm{~h}$. The collected cells were washed with cold PBS and incubated with Annexin V/propidium iodide staining (Becton, Dickinson and Company, USA) according to the manufacturer's instructions. Cell apoptosis was detected by flow cytometry and analyzed using the FlowJo software.

\section{Immunoblotting}

The cells were lysed with RIPA (Radio-Immunoprecipitation Assay) buffer (DingGuo, China) containing protease and phosphatase inhibitors (Selleck, USA). The total protein concentration in the cell lysate was determined with a BCA protein assay kit (Beyotime, China). Proteins were separated by $8-12 \%$ SDS-polyacrylamide gel electrophoresis (SDS-PAGE), transferred to polyvinylidene fluoride membranes (Millipore, USA) and incubated with primary and secondary antibodies: PARP (1:1000, CST), BCL2 (1:1000, Protech), BAX (1:1000, Protech), $\gamma \mathrm{H} 2 \mathrm{AX}(1: 1000, \mathrm{CST})$, P-ATM $(1: 1000, \mathrm{CST})$, P-ATR
(1:1000, CST), P-CHK2 (1:1000, CST), P53 (1:1000, Santa), P21 (1:1000, CST), ATM (1:1000, Protech), ATR (1:1000, Protech), CHK2 (1:1000, Protech), GAPDH (1:3000, Protech), $\beta$-actin (1:3000, Protech), and $\alpha$-tubulin (1:2000, Protech). The results were imaged using a gel image analysis system (Bio-Rad, USA) according to the manufacturer's instructions.

\section{RNA-sequencing}

The cDNA library construction, library purification and transcriptome sequencing were implemented according to the Wuhan Huada Sequencing Company's instructions.

\section{Quantitative real-time PCR analysis}

Total RNA was prepared according to the manufacturer's instructions. cDNA was synthesized by the SuperScript III First-Strand Synthesis System for reverse transcription PCR (Invitrogen, USA). qRT-PCR was performed using SYBR Green qPCR mix (Toyobo, Japan). All of the PCR primers used in this study are listed in Table 1. The qRT-PCR assays and data collection were performed on a

Table 1 The primers used in the PCR reaction and annealing

\begin{tabular}{lll}
\hline Gene name & Sequence $\left(5^{\prime}\right.$ to3') & Direction \\
\hline CDKN1A & AGCGACCTTCCTCATCCACC & Forward \\
CDKN1A & AAGACAACTACTCCCAGCCCCATA & Reverse \\
CCNE2 & ATCTCCTGGCTAAATCTCTTCTCC & Forward \\
CCNE2 & ACTGGAACTCTAATGAATCAATGGC & Reverse \\
CCNA2 & TITAGCACTCTACACAGTCACGGGA & Forward \\
CCNA2 & GGTGAAGGTCCATGAGACAAGGC & Reverse \\
CDK6 & AGAGCAAGATAATAAAGGAGATGGG & Forward \\
CDK6 & CATGTGAGACTTGAGTAGACCTGA & Reverse \\
MCM6 & GCTGTCGCACTGTAATCCTCC & Forward \\
MCM6 & ATTGATCGTGTCTATTCCCTCG & Reverse \\
BBC3 & TCTCCTCTCGGTGCTCCTTCACT & Forward \\
BBC3 & ACGTTGGCTCATTTCTCTTCA & Reverse \\
GADD45A & CTCAAGCAGTACTCCCTACAC & Forward \\
GADD45A & CTTCTTCATITTCACCTCTITCCA & Reverse \\
CDK1 & TAGTCTGGTCTTTCTTTGGCTG & Forward \\
CDK1 & GTTCAAAACTGGAATAAAACACCTA & Reverse \\
\hline
\end{tabular}


7500 real-time PCR system (Applied Biosystems, USA). Data were analyzed by using $2^{-\Delta \mathrm{CT} T}$ values.

\section{Measurement of ROS}

Cells were seeded into 6 -well plates $\left(3 \times 10^{5}\right.$ cells per well $)$ to allow attachment, incubated overnight at $37{ }^{\circ} \mathrm{C}$ in media containing $10 \%$ FBS and treated with various concentrations of VB1 or DMSO (control) for 0-12 h. The pretreated cells were then loaded with DCFH-DA (Solarbio, China) in DMEM at $37^{\circ} \mathrm{C}$ and incubated for 20 min according to the manufacturer's instructions. Excess DCFH-DA was removed by washing with DMEM. The ROS levels were measured by flow cytometry and analyzed using the FlowJo software. In a different experiment, the cells were pretreated with $5 \mathrm{mmol} / \mathrm{L} \mathrm{N}$-acetylcysteine (NAC) (Beyotime, China) for $1 \mathrm{~h}$ before exposure to VB1 and cultured for another $6 \mathrm{~h}$. The ROS levels were measured by flow cytometry and analyzed using the FlowJo software.

\section{Immunofluorescence}

Cells were seeded into 6 -well plates $\left(3 \times 10^{5}\right.$ cells per well) to allow attachment, incubated overnight at $37{ }^{\circ} \mathrm{C}$ in media containing $10 \% \mathrm{FBS}$ and treated with various concentrations of VB1 or DMSO (control) for 24 and $48 \mathrm{~h}$. The cells were then fixed with $4 \%$ paraformaldehyde and permeabilized in $0.5 \%$ Triton X-100. After blocking with $5 \%$ bovine serum albumin, the samples were incubated with $\gamma \mathrm{H} 2 \mathrm{AX}$ antibody and secondary antibody. The cells were counterstained with DAPI and visualized by fluorescence microscopy.

\section{Immunohistochemistry}

Formalin-fixed, paraffin-embedded tumor sections were baked at $65{ }^{\circ} \mathrm{C}$, deparaffinized in turpentine, rehydrated through a series of graded alcohol, and immersed in hydrogen peroxide to block endogenous peroxidase activity. Antigen retrieval was applied by heat treatment in a pressure cooker in a citrate buffer $(\mathrm{pH}$ 6.0). Sections were then blocked for nonspecific binding by incubation in normal goat serum at $37^{\circ} \mathrm{C}$. Subsequently, the slides were incubated with a primary antibody of Ki67 (1:400, Abcam), $\gamma \mathrm{H} 2 \mathrm{AX}$ (1:200, CST), P53 (1:200, Santa) at $4{ }^{\circ} \mathrm{C}$ overnight. The next day, the sections were incubated with the secondary antibody at $37{ }^{\circ} \mathrm{C}$. The slides were then added to a horseradish peroxidase-conjugated streptomycin working solution and stained with DAB reaction.

\section{Xenograft tumor model}

A total of $2 \times 10^{6} \mathrm{Sk}$-Mel-5 melanoma cells were injected subcutaneously into the right flank of 4- to 5-week-old athymic BALB/c female nude mice (nu/nu). When the tumors reached $50 \mathrm{~mm}^{3}$ or larger, the tumor-bearing mice were randomized for intraperitoneal injection of 40 or $80 \mathrm{mg} / \mathrm{kg}$ VB1 or $0.5 \%$ carboxymethyl cellulose sodium
(CMC, control) twice every other day for 2-3 weeks, with 7 mice in each group. The tumor size was measured using a caliper every other day, and the tumor volume was calculated with the formula $V=1 / 2\left(\right.$ length $\times$ width $^{2}$ ). When the tumors reached $1000 \mathrm{~mm}^{3}$, the tumor-bearing mice were sacrificed for the histological analysis.

\section{Statistical analysis}

Student's t-tests and one- or two-way ANOVA tests were conducted to analyze the data using the GraphPad Prism software (version 6.01). The quantified data are presented as the mean \pm SEM. Differences were considered to be significant when $P<0.05$.

\section{Results}

\section{VB1 suppressed the proliferation of melanoma cells}

We examined the effects of VB1 on cell viability in multiple melanoma cell lines by CCK-8 assay. As shown in Fig. 1b, c and Additional file 1: Figure S1A (upper panel), VB1 reduces cell viability in a dosage- and time-dependent manner. The IC50 values of VB1 for A375, SK-MEL-28 and SK-MEL-5 were $5 \mu \mathrm{M}, 15 \mu \mathrm{M}$ and $12 \mu \mathrm{M}$, respectively (Fig. 1c and Additional file 1: Figure S1A (lower panel)). To further evaluate the inhibitory efficacy of VB1, we treated melanoma cell lines with VB1 for $24 \mathrm{~h}$ and then assessed cellular colony formation and growth in the plates. The results showed that colony formation was suppressed by VB1 in a dosage-dependent manner (Fig. 1d and Additional file 1: Figure S1B), In addition, to determine the cellular toxicity of VB1 in normal cells, we exposed the immortalized nontumorigenic mouse skin epidermal cell line (JB6) and the human skin keratinocytes cell line (HaCat) to higher dosages of VB1. The results showed that the IC50 values of VB1 for the two cell lines were over $80 \mu \mathrm{M}$ (Fig. 1e), which is much greater than its efficacious concentration in melanoma cells. These results suggest that the cytotoxicity of VB1 was selective to melanoma cells.

\section{VB1 induced apoptosis and G2/M cell cycle arrest in melanoma cells}

To clarify the details of VB1-induced cytotoxicity in melanoma cells, we analyzed the apoptosis and cell cycle in A375, Sk-Mel-28 and Sk-Mel-5 cells and found that VB1 could significantly induce apoptosis and G2/M cell cycle arrest in a dosage-dependent manner. At a low dose of $5 \mu \mathrm{M}, \mathrm{VB} 1$ induced $17.48 \%, 16.47 \%$ and $17.03 \%$ apoptosis in A375, Sk-Mel-28 and Sk-Mel-5 cells, respectively. At a dose of $20 \mu \mathrm{M}$, the apoptosis increased to $39.6 \%, 32.4 \%$ and $39.1 \%$, respectively (Fig. $2 \mathrm{a}$ and Additional file 1: Figure S1C). In addition, $5 \mu \mathrm{M}$ VB1 caused a change in the cell cycle distribution in the $G 2 / \mathrm{M}$ phase arrest, whereas $20 \mu \mathrm{M}$ VB1 significantly induced arrest at G2/M phase by decreasing the distribution of G0/G1 phase (Fig. 2b and Additional file 1: Figure S1D). Next, we 

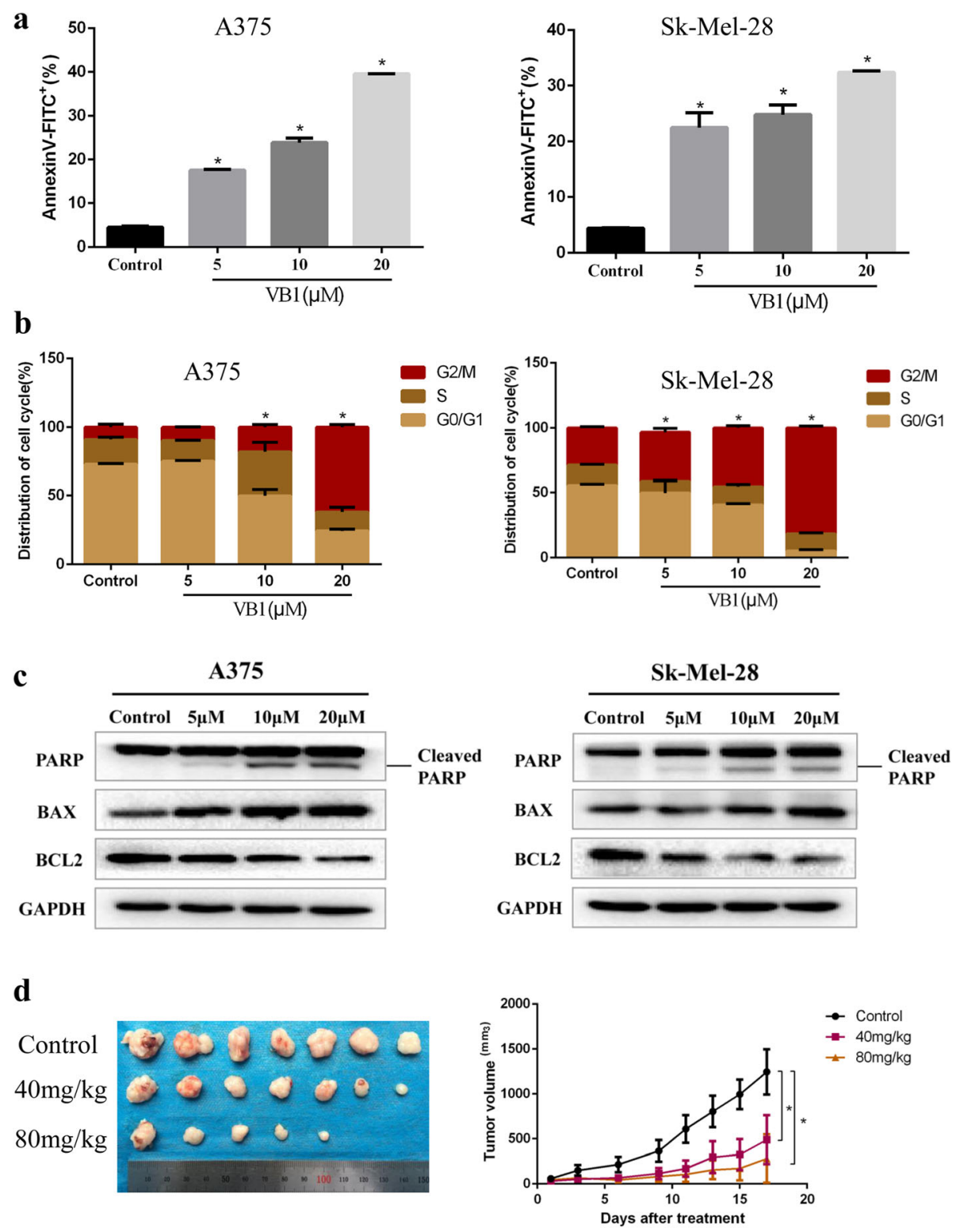

Fig. 2 VB1 treatment induces apoptosis and cell cycle arrest in melanoma cells. a A375 and Sk-Mel-28 cells were treated with various dosages of VB1 for $48 \mathrm{~h}$, and the extent of apoptosis was determined by flow cytometry with Annexin $\mathrm{V}$ and PI double staining as described in the Methods. The results represent the mean $(n=4) \pm$ SD of each group, and an asterisk $\left(^{*}\right)$ indicates a significant difference using one-way ANOVA ( $\left.p<0.05\right)$. b A375 and Sk-Mel-28 cells were treated with various dosages of VB1 for $48 \mathrm{~h}$. The cell cycle distribution was detected by flow cytometry as described in the Methods. The results represent the mean $(n=4) \pm$ SD of each group, and an asterisk $\left.*^{*}\right)$ indicates a significant difference using one-way ANOVA $(p<0.05)$. c A375 and Sk-Mel-28 cells treated with various dosages of VB1 were lysed, and western blotting was then performed for the indicated antibodies. $\mathbf{d}$ Sk-Mel-5 melanoma cells $\left(2 \times 10^{6}\right.$ cells $\left./ 0.15 \mathrm{~mL}\right)$ were xenografted into nude mice. When the tumors reached approximately $50 \mathrm{~mm}^{3}$, the tumor-bearing mice were randomized for intraperitoneal injection of $40 \mathrm{or} 80 \mathrm{mg} / \mathrm{kg}$ of VB1 twice every other day for 2-3 weeks as described in the Methods. The tumor growth and body weight were measured twice per week. The results are shown as the mean tumor volume $\pm \mathrm{SD}$, and an asterisk $\left(^{*}\right)$ indicates a significant difference $(p<0.05$ one-way ANOVA)

examined the expression of apoptotic markers during VB1 treatment. The results showed that VB1 induced cleavage of PARP and upregulated BAX expression, whereas BCL2 expression was downregulated after VB1 treatment in different melanoma cell lines (Fig. $2 \mathrm{c}$ and Additional file 1: Figure S1E). To examine the effect of VB1 on cancer cell growth in vivo, a xenograft study was performed in nude mice, as shown in Fig. 2 d. The results were consistent with the in vitro results; VB1 completely attenuated the growth of the xenografted melanoma cells, and there was no significant change in the body weight of the tumor-bearing mice (Fig. 2d and Additional file 1: Figure S1F, G). 


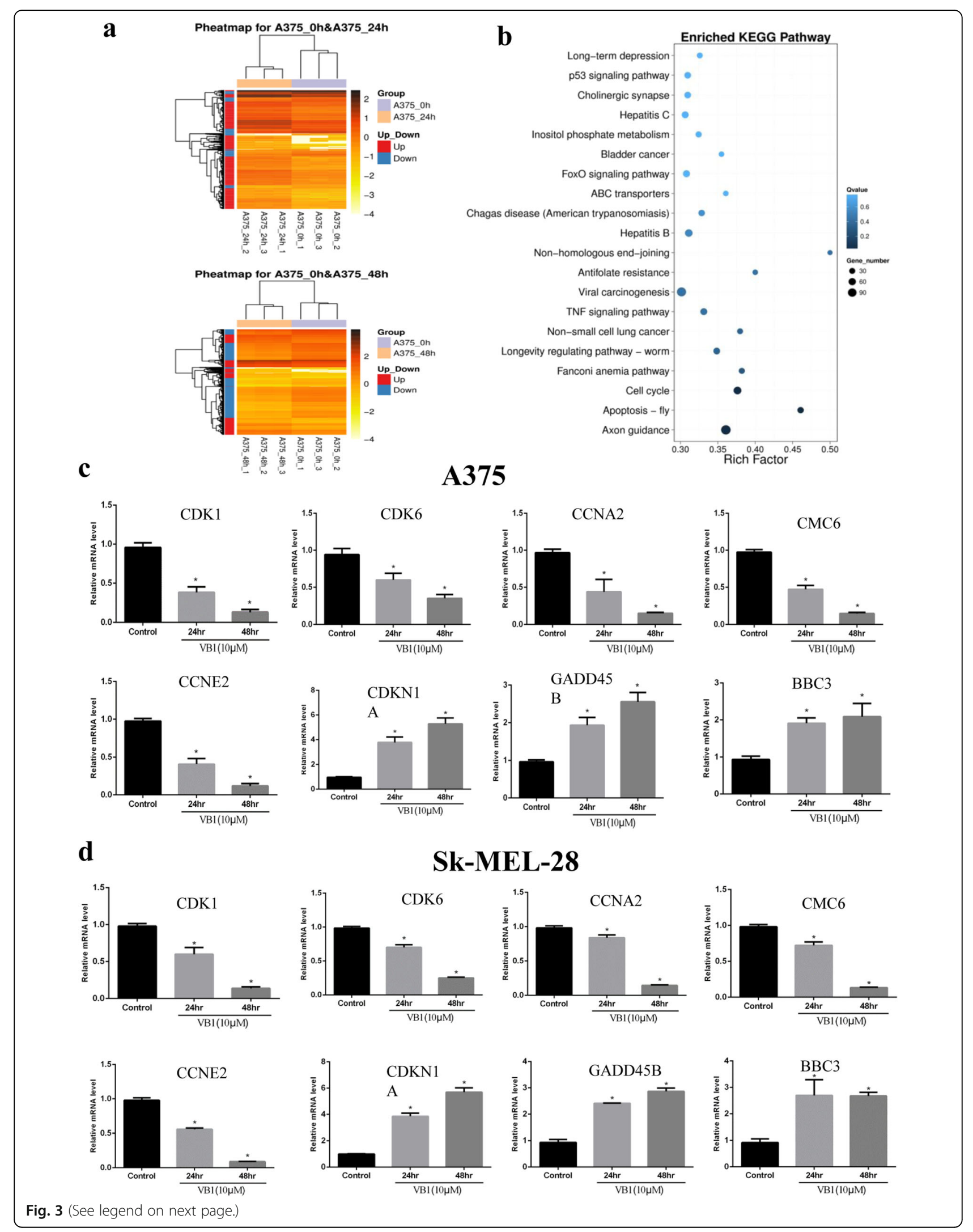


(See figure on previous page.)

Fig. 3 RNA-seq analyses of the effect of VB1 on the gene expression profile. a A375 cells were treated with $10 \mu M$ VB1 for 48 h. RNA-seq was performed as described in the Methods, and differential expression genes were analyzed using DESeq2. $\mathbf{b}$ The KEGG pathway was used to analyze the pathways related to the differential expression genes. The top 20 positively enriched pathways are shown in the bubble chart. The $x$ axis is the enrichment score, and the $y$-axis is the enriched pathways. c \& d RNA was extracted from A375 (c) and Sk-Mel-28 (d) treated with VB1 as indicated, and RT-Q-PCR was then performed as described in the Methods. The data from multiple experiments are expressed as the mean $(n=4) \pm$ S.D. Significant differences were evaluated using one-way ANOVA, and an asterisk $\left.{ }^{*}\right)$ indicates a significant difference $(p<0.05)$

\section{Effect of VB1 on the gene expression profile and the alteration of key pathways}

To further study the possible mechanisms of VB1's antitumor effects, we analyzed the global transcriptome alteration of melanoma cells after VB1 treatment in different melanoma cell lines. The RNA-seq results showed that 409 genes were upregulated and 102 genes were downregulated after VB1 treatment for $24 \mathrm{~h}$, whereas 2538 genes were upregulated and 3950 genes were downregulated after $48 \mathrm{~h}$ of treatment (Fig. 3a). Similar results were observed in Sk-Mel-5 cells (Additional file 2: Figure S2A (left panel)). We analyzed differential expression genes by the Kyoto Encyclopedia of Genes and Genomes (KEGG) pathway. These genes are involved in multiple pathways, such as JAK-STAT, FOXO, TNF and cell cycle-related pathways (Fig. 3b and Additional file 2: Figure S2A (right panel)). We identified pivotal pathways involved in p53, DNA damage and the cell cycle, which was consistent with the effect of VB1 on G2/M arrest in different melanoma cell lines. Next, we validated the key differential expression genes by Q-RT-PCR. Consistent with the RNA-seq results, the alteration of several genes, including $P 21$ (CDKN1A), PUMA (BBC3), CYCE (CCNE), CYCA (CCNA), CDK1, $C D K 6$ and $M C M 6$, were confirmed, all of which play crucial roles in cell cycle regulation (Fig. 3c, $d$ and Additional file 2: Figure S2B).

\section{VB1 induced DNA damage by increasing intracellular ROS in melanoma cells}

Based on the previous results, which showed that VB1 treatment induced significant apoptosis and G2/M arrest in melanoma cells, we proposed that VB1 might induce DNA toxicity and result in cellular apoptosis and G2/M cell cycle arrest. As expected, VB1 treatment significantly increased p53, P-ATM, P-ATR, P-CHK2 and $\gamma \mathrm{H} 2 \mathrm{AX}$ expression in a dosage-dependent manner. There were no significant changes in the expression of total ATM, ATR and CHK2 protein level (Fig. 4a and Additional file 3: Figure S3A). In addition, the accumulation of $\gamma \mathrm{H} 2 \mathrm{AX}$ was observed in the nucleus (Fig. 4b, c and Additional file 3: Figure S3B, C), which suggests that this compound induced DNA damage. We also examined Ki67, P53 and $\gamma \mathrm{H} 2 \mathrm{AX}$ expression in paraffin-embedded mice tumor tissues. The findings showed that P53 and $\gamma \mathrm{H} 2 \mathrm{AX}$ expression increased significantly after VB1 treatment and that the expression of Ki67 was inhibited (Additional file 3: Figure S3D), which was consistent with the results of the VB1 inhibition of xenografted melanoma cell growth (Fig. 2d) and induction of DNA damage. Oxidative damage is well-known to play dual roles in carcinogenesis and ROS-based anticancer treatment. At low or moderate levels, ROS regulate essential biological functions of cells, including proliferation, angiogenesis and tumor metastasis, whereas at higher levels, ROS affect cells by causing DNA damage and apoptosis that leads to therapeutic effects on cancer [23]. Our results showed that VB1 treatment dramatically increases intracellular ROS levels in different melanoma cell lines (Fig. 4d and Additional file 3: Figure S3E (left panel)), which could be partly impeded by antioxidant $\mathrm{N}$-acetylcysteine (NAC) (Fig. 4e and Additional file 3: Figure S3E (right panel)). All of those indicates that VB1 treatment promotes the accumulation of ROS and leads to DNA damage in melanoma cells.

\section{VB1 attenuated BRAFi-resistant melanoma cell growth}

V600E mutations in BRAF occur commonly in cutaneous melanoma, and its targeted inhibitors, including vemurafenib, have been administered by the FDA as therapy for advanced melanoma patients with BRAF mutations. However, most patients encounter BRAFi resistance after inhibitor treatment. Therefore, we examined the effects of VB1 on BRAFi-resistant cells. BRAFi-resistant A375 was generated by continual treatment with PLX4720 $(2 \mu \mathrm{M})$ for more than 3 months to obtain a "resistant" cell line (labeled RA) (Fig. 5a). The results showed that VB1 dramatically inhibited cell viability in a dosage- and time-dependent manner and that the IC50 value of VB1 was approximately $5 \mu \mathrm{M}$ (Fig. $5 \mathrm{~b}$ ). Furthermore, the growth of melanoma cell colonies in plates was sharply reduced by VB1 treatment (Fig. 5c). Next, we analyzed the apoptosis and cell cycle in RA cells by VB1. As shown in Fig. 5d, left panel, VB1 induced 18.95\% apoptosis at $5 \mu \mathrm{M}$ and $33.3 \%$ apoptosis at $20 \mu \mathrm{M}$. As a result, the cleavage of PARP, BAX and BCL2 was affected significantly by VB1 treatment (Fig. 5d, right panel). For the cell cycle analysis, VB1 treatment resulted in significant arrest at $\mathrm{G} 2 / \mathrm{M}$ phase and decreased the distribution of cells in G0/G1 phase (Fig. 5e). 


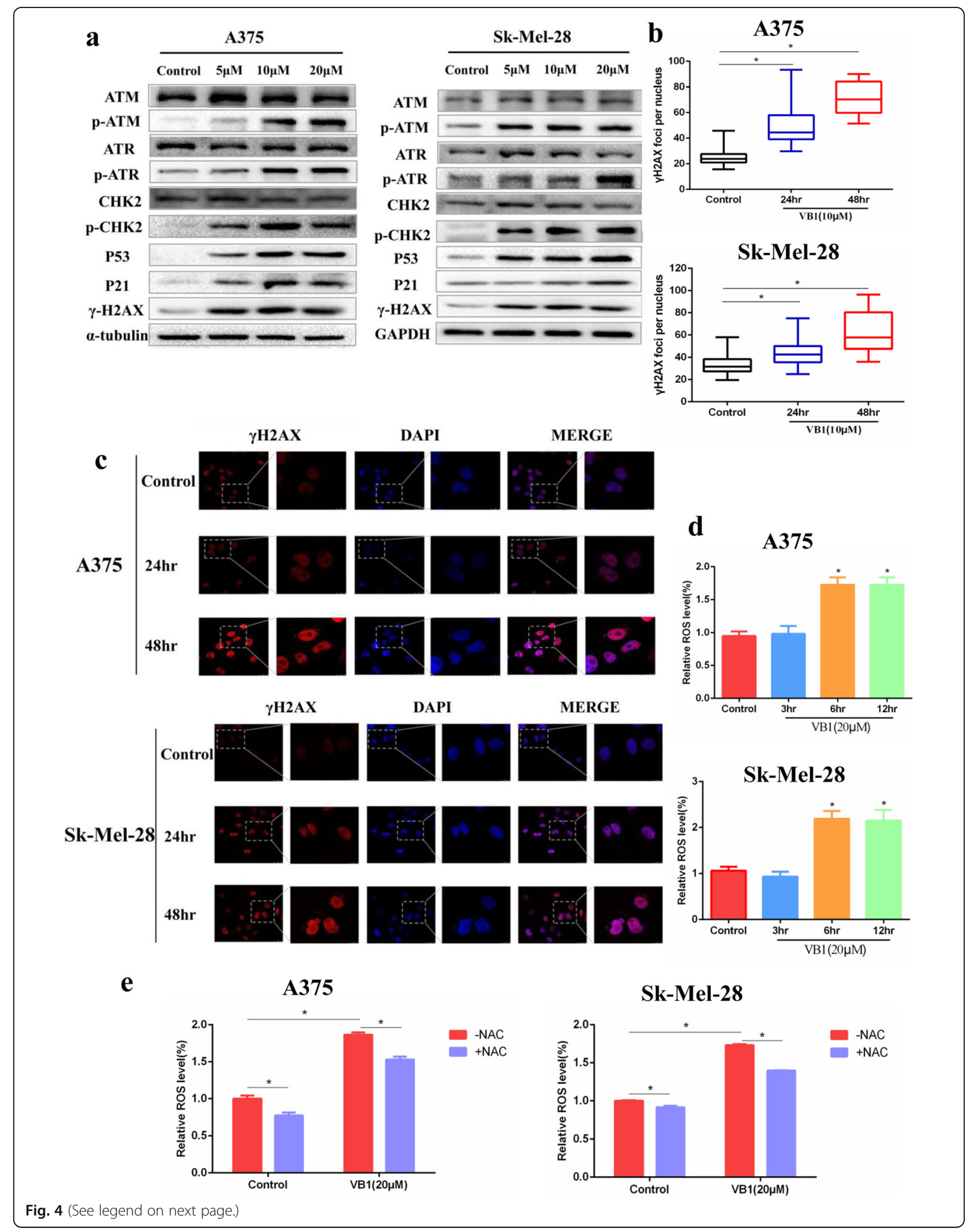


(See figure on previous page.)

Fig. 4 VB1 treatment induces DNA damage by increasing ROS. a A375 (left panel) and Sk-Mel-28 (right panel) cells were treated with 0-20 $\mu$ M VB1 for $48 \mathrm{~h}$, and western blotting was then performed for the indicated antibodies. b A375 and Sk-Mel-28 cells were treated with $10 \mu \mathrm{M}$ VB1 for $0-48 \mathrm{~h}$, and $\mathrm{\gamma H} 2 \mathrm{AX}$ was stained by immunofluorescence and calculated. The results represent the mean $(n=5) \pm \mathrm{SD}$ of each group, and an asterisk $\left(^{*}\right)$ indicates a significant difference using one-way ANOVA $(p<0.05)$. c A375 and Sk-Mel-28 cells were treated with $10 \mu \mathrm{M}$ VB1 for 0-48 h, and $\mathrm{YH} 2 \mathrm{AX}$ was stained by immunofluorescence. Representative images of staining of $\mathrm{YH} 2 \mathrm{AX}$. $\mathbf{d}$ A375 and Sk-Mel-28 cells were treated with $20 \mu \mathrm{M}$ VB1 for 0-12 h. The levels of ROS were measured by DCF fluorescence with flow cytometry. The relative ROS levels were analyzed using the GraphPad Prism software (histogram). e A375 and Sk-Mel-28 cells were pretreated with $5 \mathrm{mmol} / \mathrm{L}$ N-acetylcysteine (NAC) for $1 \mathrm{~h}$, and then, exposed to $20 \mu \mathrm{M}$ VB1 for another $6 \mathrm{~h}$. The levels of ROS were measured by DCF fluorescence with flow cytometry. The relative ROS levels were analyzed using the GraphPad Prism software (histogram). The results represent the mean $(n=4) \pm$ SD of each group, and an asterisk (*) indicates a significant difference using one-way ANOVA $(p<0.05)$

We then performed RNA-seq to investigate the molecular mechanism of VB1 in RA cells. As shown in Additional file 4: Figure S4A, we found that the differential expression genes were enriched in JAK-STAT, FOXO, TNF and cell cycle signaling pathways and particularly the cell cycle pathway, which is similar to the results of the non-BRAFi-resistant melanoma cell lines. We verified the key differential expression genes in RA cells, which showed that the P21 (CDKN1A), PUMA $(B B C 3)$ and $G A D D 45 A$ expression levels increased significantly and that the CDK1, CDK6, CYCE (CCNE), $M C M 6$ and $C Y C A$ (CCNA) genes were significantly down-regulated (Additional file 4: Figure S4B).

The previous results showed that VB1 could induce DNA damage through upregulation of the ROS level in melanoma cells. Therefore, we examined the effect of VB1 on DNA damage and the ROS level in BRAFi-resistant cells. The results indicated that VB1 increased P53 and the expression of its downstream molecule, P21, as well as P-ATM, P-ATR, P-CHK2 and $\gamma \mathrm{H} 2 \mathrm{AX}$. There were no significant changes in the expression of total ATM, ATR and CHK2 protein level (Fig. 6a). In addition, we observed the accumulation of $\gamma \mathrm{H} 2 \mathrm{AX}$ in the nucleus of BRAFi-resistant cells (Fig. 6b, c). We also determined the intracellular ROS levels after VB1 treatment, which demonstrated that the role of VB1 in BRAFi-resistant cells was similar to that in nonresistant melanoma cell lines. Our results showed that VB1 treatment dramatically increases intracellular ROS levels in RA (Fig. 6d (left panel)), which could be partly impeded by antioxidant $\mathrm{N}$-acetylcysteine (NAC) (Fig. 6d (right panel)). this indicates that VB1 could be used for the treatment of BRAFi-resistant melanoma patients.

\section{Discussion}

In this study, we found that VB1 significantly blocks cell growth in various melanoma cell lines, including A375, Sk-Mel-28 and Sk-Mel-5, in vitro (Fig. 1b, d) and in vivo (Fig. 2d). Given the unbearable toxicity or side effects of chemotherapeutic drugs or targeted inhibitors that lead to failure in clinical treatments, we also examined the toxic effects of VB1. We treated immortalized nontumorigenic mouse skin epidermal JB6 and human skin keratinocyte (HaCat) cells with various concentrations of VB1, and the results showed that the IC50 values of VB1 for the two cell lines were over $80 \mu \mathrm{M}$ (Fig. 1e), whereas the IC50 values in melanoma cells were $5.03 \mu \mathrm{M}$ for A375 and $15.83 \mu \mathrm{M}$ for SK-MEL-28 (Fig. 1c). These results indicate that the cytotoxicity of VB1 is selective to tumor cells. Our results are consistent with those of a previous study, which showed that VB1 was well tolerated in tumor-bearing mice with no significant differences in the body serum levels of alanine aminotransferase, aspartate aminotransferase, creatinine, white blood cell and erythrocyte counts between the VB1 treated group and the control group [20]. We also found that VB1 could cause apoptosis and induce cell cycle arrest in G2/M phase (Fig. 2a, b). In addition, the expression of cleaved PARP and Bax increased after VB1 treatment, whereas that of BCL2 decreased (Fig. 2c), which indicates that VB1 induces melanoma cell apoptosis.

Next, we performed RNA-seq to investigate the effect of VB1 on the signaling pathways. The p53 pathway, cell cycle pathway and apoptosis pathway were shown to be significantly altered after VB1 treatment (Fig. 3b). Furthermore, we verified key gene expression with mRNA levels after treatment with VB1 in melanoma cells, which indicated that the P21, PUMA and GADD45A expression was significantly upregulated and that the expression of $M C M 6, C D K 1, C D K 6, C Y C E$ and $C Y C A$ was significantly downregulated (Fig. 3c, d). These genes are crucial mediators in the cell cycle, apoptosis and DNA damage [24, 25]. P21, which is also called Cip1 or CDKN1A, inhibits several cyclin-dependent kinases and induces cell cycle arrest. GADD45 can induce DNA damage and cell cycle arrest in the $\mathrm{G} 2 / \mathrm{M}$ phase by directly regulating DNA nucleotide excision repair [26, 27]. PUMA, which is a downstream molecule of P53, can lead to apoptosis by inducing intracellular ROS and DNA damage $[28,29]$. Therefore, these differentially expressed genes may provide a molecular mechanism for how VB1 treatment dramatically induces cell cycle arrest in G2/M phase in melanoma cells.

P53- and P53-related signaling pathways play crucial roles in tumorigenesis. P53 is an important DNA damage response (DDR) component, allowing to repair limited 

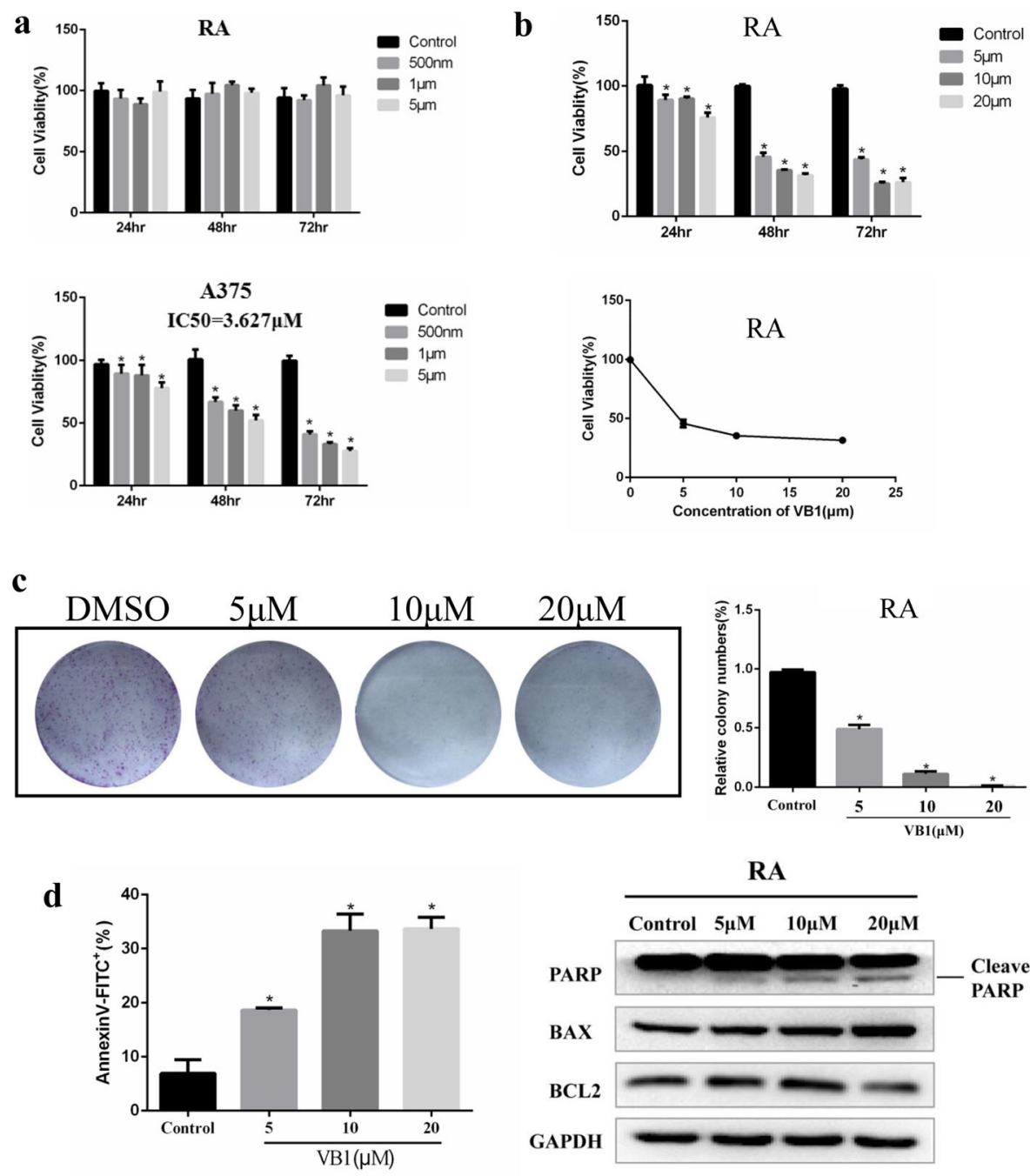

RA

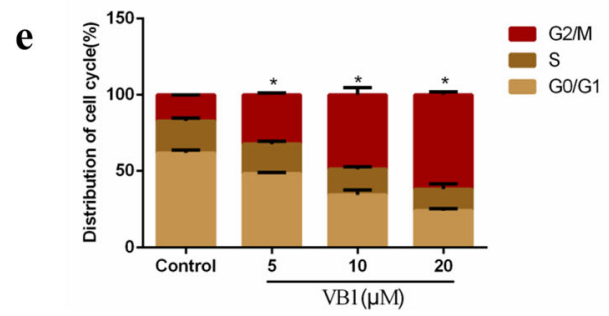

Fig. 5 Effect of VB1 on BRAFi-resistant melanoma cells. a BRAFi-resistant melanoma cells (RA) from parental A375 were generated as described in the Methods. RA and parental A375 cells were seeded into 96-well plates and then treated with PLX4072. Cell viability was determined by the CCK-8 assay. The results represent the mean $(n=6) \pm$ SD of each group, and an asterisk $\left(^{*}\right)$ indicates a significant difference using one-way ANOVA $(p<0.05)$. b RA cells were treated with $0-20 \mu \mathrm{M}$ VB1 for $0-72 \mathrm{~h}$. Cell viability was determined by the CCK-8 assay. The IC50 values of VB1 in the RA cells were automatically generated by the GraphPad Prism software. $\mathbf{c}$ RA cells were seeded into 6-well plates and then treated with various dosages of VB1 as indicated for $24 \mathrm{~h}$. After 10-14 days, the number of colonies was assessed and quantified by crystal violet staining as described in the Methods. $\mathbf{d}$ RA cells were seeded into 6-well plates after being treated with VB1 at various dosages, and the apoptosis was determined by flow cytometry with Annexin V and PI double staining. The cell lysates were prepared from RA cells treated with VB1 at various dosages, and western-blotting was performed by various antibodies as indicated. e RA cells were seeded into 6-well plates after being treated with VB1 at various dosages, and the distribution of the cell cycle was determined by flow cytometry as described in the Methods. The results represent the mean $(n=4) \pm$ SD of each group, and an asterisk (*) indicates a significant difference using one-way ANOVA $(p<0.05)$ 

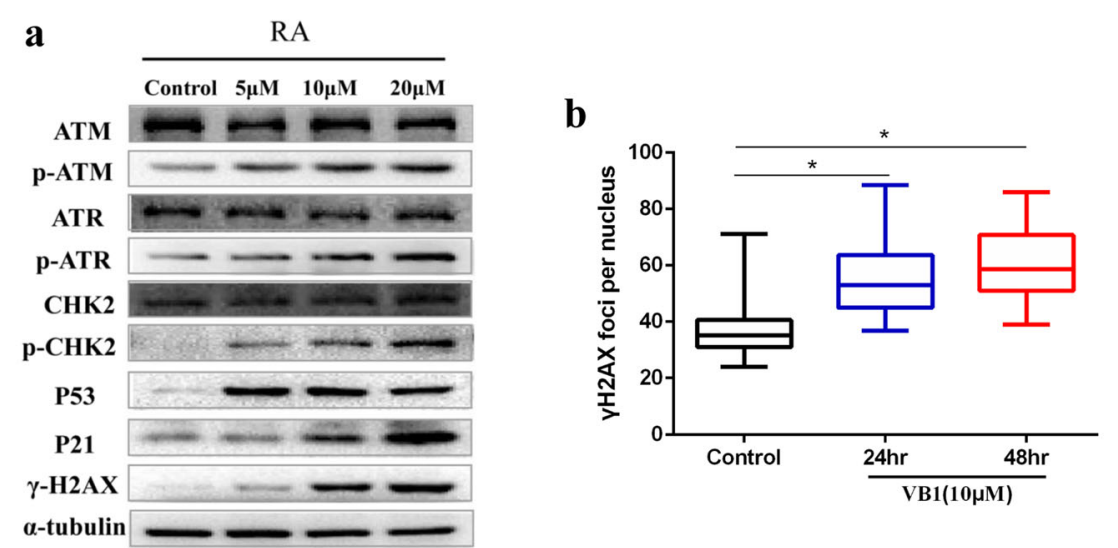

c

$\gamma \mathrm{H} 2 \mathrm{AX}$

DAPI

MERGE
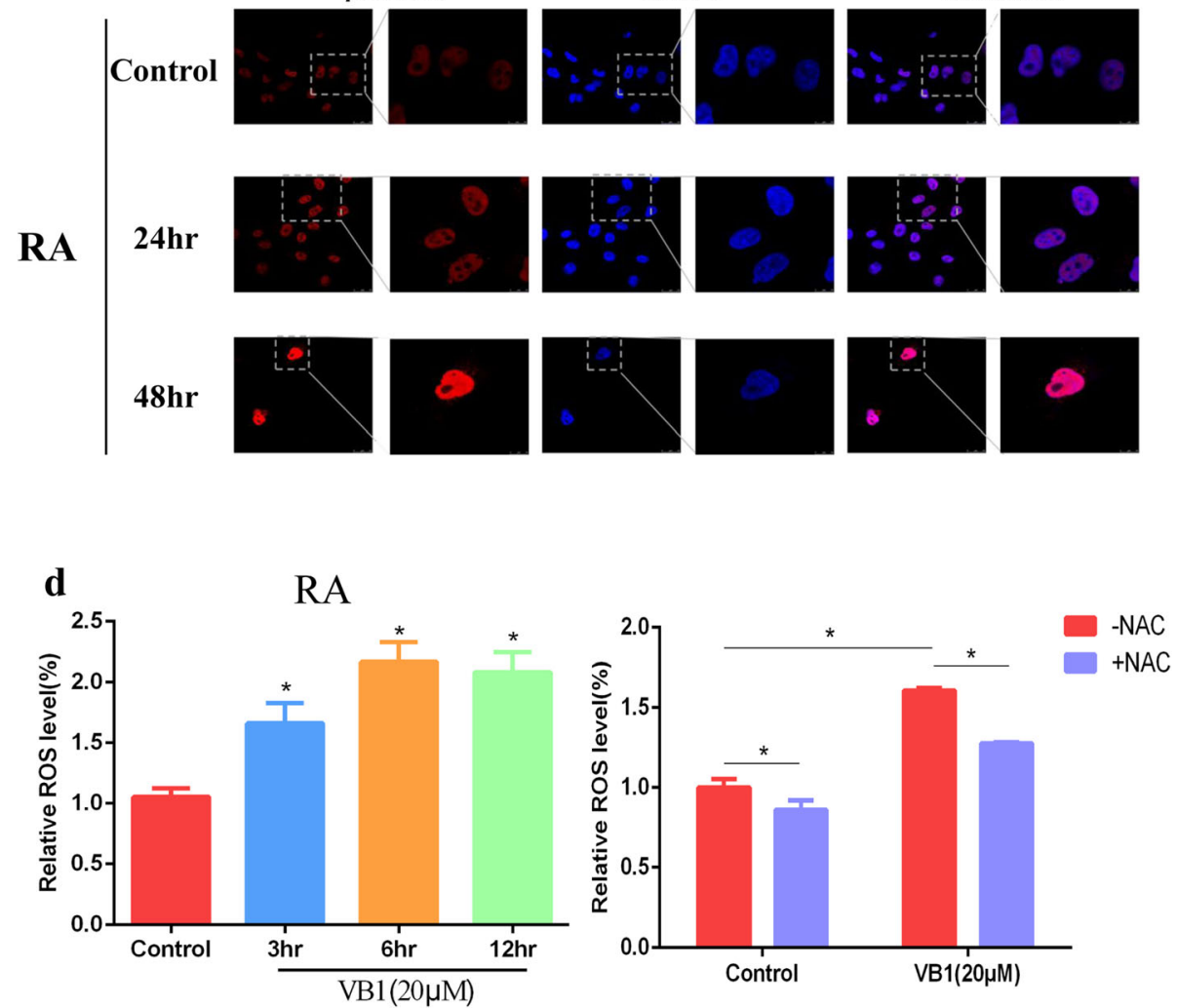

Fig. 6 VB1 induces DNA damage by increasing ROS in RA cells. a RA cells were treated with 0-20 $\mu \mathrm{M}$ VB1 for 48 h, and western blotting was then performed for the indicated antibodies. $\mathbf{b} \& \mathbf{c}$ RA cells were treated with $10 \mu \mathrm{M} V B 1$ for $0-48 \mathrm{~h}$, and $\gamma \mathrm{H} 2 \mathrm{AX}$ was stained by immunofluorescence $(\mathbf{c})$, the foci of $\mathrm{YH} 2 \mathrm{AX}$ was quantificated $(\mathbf{b})$, the results represent the mean $(n=5) \pm \mathrm{SD}$ of each group, and an asterisk $(*)$ indicates a significant difference using one-way ANOVA $(p<0.05)$. d RA cells were treated with $20 \mu \mathrm{M}$ VB1 for $0-12 \mathrm{~h}$. The levels of ROS were measured by DCF fluorescence with flow cytometry. The relative ROS levels were analyzed by GraphPad Prism software (histogram) (left panel). RA cells were pretreated with $5 \mathrm{mmol} / \mathrm{L} \mathrm{N}$-acetylcysteine (NAC) for $1 \mathrm{~h}$, and then exposed to $20 \mu \mathrm{M}$ VB1 for another $6 \mathrm{~h}$. The levels of ROS were measured by DCF fluorescence with flow cytometry. The relative ROS levels were analyzed using the GraphPad Prism software (histogram) (right panel). The results represent the mean $(n=4) \pm$ SD of each group, and an asterisk (*) indicates a significant difference using one-way ANOVA $(p<0.05)$

DNA damage through cell cycle arrest or to eliminate cells with severe DNA damage via apoptosis [30, 31]. A variety of DNA toxicity stresses could activate P53- and p53-related pathways and lead to transactivation of downstream target genes to regulate the cell cycle, apoptosis and DNA damage repair [32, 33]. Although inactivation mutations or allele deletions of P53 are common in human cancers, more than $80 \%$ of human melanomas express P53 with a wild-type (WT) sequence, and the induction of P53 expression could 
significantly inhibit melanoma cell growth [34]. Our results showed that VB1 could induce G2/M arrest and apoptosis, which indicates that this compound might cause DNA toxicity for cells. As expected, our findings showed that DNA damage-related proteins [24, 35, 36], including P-ATM, P-ATR, P-CHK2 and $\gamma \mathrm{H} 2 \mathrm{AX}$ as well as P53 and its downstream P21, were significantly increased after VB1 treatment (Fig. 4a), which suggests that VB1 inhibits melanoma cell growth through DNA damage that eventually leads to P53 pathway-related cell cycle arrest and apoptosis.

In general, DNA toxicity stresses involve IR, radiomimetic compounds, topo I/II inhibitors, UV, $\mathrm{H}_{2} \mathrm{O}_{2}$ and ROS [36]. Of these stresses, reactive oxygen species (ROS) constitute a group of highly reactive small molecules, including $\mathrm{H}_{2} \mathrm{O}_{2}$, superoxide $\left(\mathrm{O}^{2-}\right)$ and hydroxyl radicals [37]. Although ROS facilitates the progression of cancer to some extent, the accumulation of ROS reaches a threshold and then causes cell death [23]. Therefore, increasing the ROS level to induce cancer cell death is a well-known anticancer strategy [38-40]. Evidence shows that pharmaceutical compounds extracted from plants, such as resveratrol, levistolide A and piperlongumine, induce apoptosis through DNA toxicity by the induction of intracellular ROS [40-42]. In this study, we measured the level of intracellular ROS in melanoma after VB1 treatment, and the results showed that VB1 significantly increases ROS levels, which indicates that the cells were under high oxidative stress. $\gamma \mathrm{H} 2 \mathrm{AX}$ is an indicator of DNA damage that accumulates in the nucleus and indicates the presence of DNA damage [43, 44]. In this study, we found that $\gamma \mathrm{H} 2 \mathrm{AX}$ increased in the nucleus after VB1 treatment in a time-dependent manner, which indicates that VB1 caused DNA damage, G2/M cycle arrest and apoptosis by increasing intracellular ROS (Fig. 6).

The administration of BRAF inhibitors benefits the OS and RFS of melanoma patients; however, after approximately 6 months of treatment, patients experience fatal drug resistance or the recurrence of metastases. The reactivation of MAPK signaling is involved in BRAFi resistance, such as bypass activation in RAF, MEK $1 / 2$ and NRAS [10, 45, 46]. In addition, EGFR-STAT3, CDK2 and AXL/AKT signaling pathways play critical roles in BRAFi resistance in melanoma [12, 47, 48]. Interestingly, we found that VB1 could also significantly inhibit the growth of RA. The IC50 values are similar to

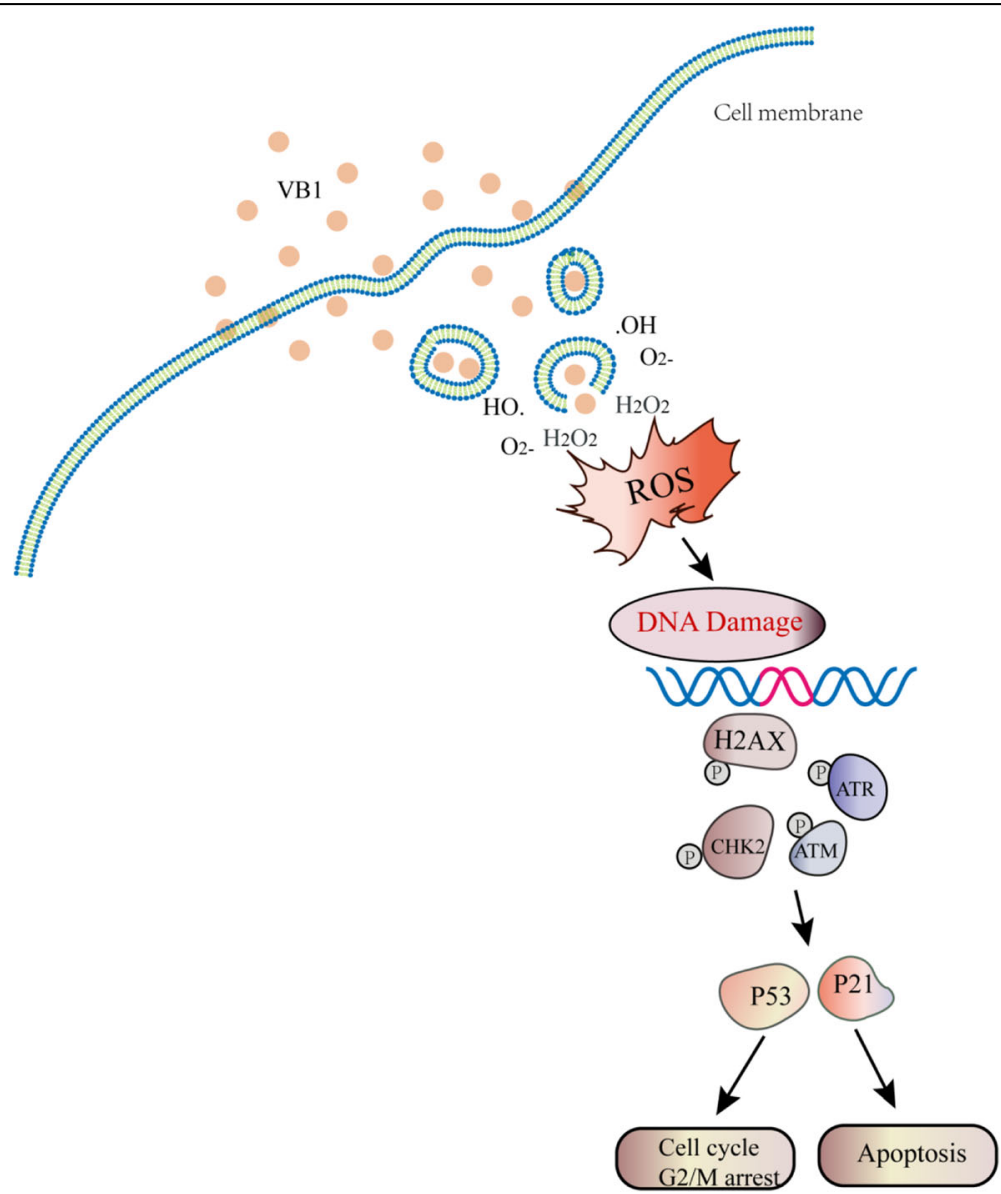

Fig. 7 Schematic diagram of the mechanism of action of VB1. VB1 kills cancer cells by accumulating intracellular ROS, which leads to DNA damage, G2/M cell cycle arrest and apoptosis in melanoma cells 
those of its parental cells (approximately 3-5 $\mu \mathrm{M}$ ), which indicates that VB1 could completely overcome the BRAFi resistance of melanoma. Similar to nonresistant melanoma cell lines, VB1 also increases intracellular ROS levels and induces DNA damage, leading to melanoma cell cycle arrest and apoptosis (Figs. 5, 6), which suggests that VB1 is applicable to BRAFi-resistant melanoma patients.

\section{Conclusions}

In summary, we demonstrated that VB1 promotes the accumulation of intracellular ROS, resulting in DNA damage, G2/M cell cycle arrest and apoptosis in melanoma cells and BRAFi-resistant melanoma cells, which provides evidence for the application of VB1 as an antimelanoma treatment (Fig. 7).

\section{Additional files}

Additional file 1: Figure S1. VB1 inhibits melanoma cells growth in vitro and in vivo. (A) Sk-Mel-5 cells were prepared in 96-well plates. The cells were treated with VB1 for various times and dosages as indicated, and cell viability was tested by CCK-8 as described in the Materials and Methods. The results represent the mean $(n=6) \pm \mathrm{SD}$ of each group, and an asterisk $\left(^{*}\right)$ indicates a significant difference using one-way ANOVA $(p<0.05)$. The IC50 values of VB1 in Sk-Mel-5 were automatically calculated by GraphPad Prism software as described in the Materials and Methods (lower panel). (B) Sk-Mel-5 cells were seeded into 6-well plates and then treated with various dosages of VB1 as indicated for $24 \mathrm{~h}$. After 10-14 days, the number of colonies was assessed and quantified by crystal violet staining as described in the Materials and Methods. (C) Sk-Mel-5 cells were treated with various dosages of VB1 for $48 \mathrm{~h}$, and the extent of apoptosis was determined by flow cytometry with Annexin V and PI double staining as described in the Materials and Methods. (D) Sk-Mel-5 cells treated with various dosages of VB1 were lysed, and western blotting was then performed for the indicated antibodies. (E) Sk-Mel-5 cells were treated with various dosages of VB1 for $48 \mathrm{~h}$. The cell cycle distribution was detected by flow cytometry as described in the Materials and Methods. The results represent the mean $(n=4) \pm$ SD of each group, and an asterisk $\left(^{*}\right)$ indicates a significant difference using one-way ANOVA $(p<0.05)$. (F) Sk-Mel-5 melanoma cells $\left(2 \times 10^{6}\right.$ cells/ $0.15 \mathrm{~mL}$ ) were xenografted into nude mice. When the tumors reached approximately $50 \mathrm{~mm}^{3}$, the tumor-bearing mice were randomized for intraperitoneal injection of 40 or $80 \mathrm{mg} / \mathrm{kg}$ of VB1 twice every other day for 2-3 weeks as described in the Materials and Methods. The overview of nude mice were showed. (G) The tumor body weight were measured twice per week. The results are shown as the mean tumor volume $\pm S D$, and an asterisk $\left(^{*}\right)$ indicates a significant difference ( $p<0.05$ one-way ANOVA). (TIF $6050 \mathrm{~kb}$ )

Additional file 2: Figure S2. RNA-seq analyses of the effect of VB1 on the gene expression profile in SK-MEL-5 cells. (A) SK-MEL-5 cells were treated with $10 \mu \mathrm{M}$ VB1 for $48 \mathrm{~h}$. RNA-seq was performed as described in the Materials and Methods, and differential expression genes were analyzed using DESeq2. The KEGG pathway was used to analyze the pathways related to the differential expression genes. The top 20 positively enriched pathways are shown in the bubble chart. The $x$-axis is the enrichment score, and the $y$ axis is the enriched pathways. (B) RNA was extracted from Sk-Mel-5 treated with VB1 as indicated, and RT-Q-PCR was then performed as described in the Materials and Methods. The data from multiple experiments are expressed as the mean \pm S.D. Significant differences were evaluated using one-way ANOVA, and an asterisk (*) indicates a significant difference $(p<0.05$ ). (TIF $3060 \mathrm{~kb})$

Additional file 3: Figure S3. VB1 treatment induces DNA damage by increasing ROS in vitro and in vivo. (A) Sk-Mel-5 cells were treated with $0-20 \mu \mathrm{M}$ VB1 for $48 \mathrm{~h}$, and western blotting was then performed for the indicated antibodies. (B) Sk-Mel-5 cells were treated with $10 \mu \mathrm{M}$ VB1 for $0-48 \mathrm{~h}$, and $\mathrm{\gamma H} 2 \mathrm{AX}$ was stained by immunofluorescence and calculated.
The results represent the mean $(n=5) \pm S D$ of each group, and an asterisk ${ }^{*}$ ) indicates a significant difference using one-way ANOVA $(p<0.05)$. (C) Sk-Mel-5 cells were treated with $10 \mu \mathrm{M}$ VB1 for $0-48 \mathrm{~h}$, and $\mathrm{\gamma H} 2 \mathrm{AX}$ was stained by immunofluorescence. Representative images of staining of YH2AX. (D) Sk-Mel-5 cells were treated with $20 \mu \mathrm{M}$ VB1 for 0-12 h. The levels of ROS were measured by DCF fluorescence with flow cytometry. The relative ROS levels were analyzed using the GraphPad Prism software (histogram) (left panel). Sk-Mel-5 cells were pretreated with $5 \mathrm{mmol} / \mathrm{L} \mathrm{N}$ acetylcysteine (NAC) for $1 \mathrm{~h}$, and then, exposed to $20 \mu \mathrm{M}$ VB1 for another $6 \mathrm{~h}$. The levels of ROS were measured by DCF fluorescence with flow cytometry. The relative ROS levels were analyzed using the GraphPad Prism software (histogram) (right panel). The results represent the mean $(n=4) \pm$ SD of each group, and an asterisk $\left(^{*}\right)$ indicates a significant difference using one-way ANOVA $(p<0.05)$. (D) The immunohistochemistry was performed as indicated antibodies as described in the Materials and Methods. (TIF $8570 \mathrm{~kb}$ )

Additional file 4: Figure S4. RNA-seq analyses of the effect of VB1 on the gene expression profile in RA cells (A) RA cells were treated with 10 $\mu \mathrm{M} V \mathrm{~V} 1$ for $48 \mathrm{~h}$. RNA-seq was performed as described in the Materials and Methods, and differential expression genes were analyzed using DESeq2. The KEGG pathway was used to analyze the pathways related to the differential expression genes. The top 20 positively enriched pathways are shown in the bubble chart. The $x$-axis is the enrichment score, and the $y$ axis is the enriched pathways. (B) RNA was extracted from RA treated with VB1 as indicated, and RT-Q-PCR was then performed as described in the Materials and Methods. The data from multiple experiments are expressed as the mean \pm S.D. Significant differences were evaluated using one-way ANOVA and an asterisk (*) indicates a significant difference $(p<0.05)$. (TIF $3770 \mathrm{~kb}$ )

\section{Abbreviations}

BRAFi: BRAF inhibitor; CCK8: Cell counting kit; DCFH-DA: 2,7-Dichlorodi hydrofluorescein diacetate; DMEM: Dulbecco's modified Eagle's medium; DMSO: Dimethyl sulfoxide; EDTA: Ethylene Diamine Tetraacetic Acid; FBS: Fatal bovine serum; FDA: Food and Drug Administration; IC50: half maximal inhibitory concentration; MEKi: Mitogen-activated protein kinase kinase inhibitor; PBS: Phosphate Buffered Saline; RIPA: RadioImmunoprecipitation Assay; ROS: Reactive oxygen species; SDS-PAGE: SDSpolyacrylamide gel electrophoresis; VB1: Vitexin compound 1

\section{Funding}

This work was supported by the National Natural Science Foundation of China (Grants No. 81572679, 81472852, 81772917) and supported by Major Projects of International Cooperation and Exchanges NSFC Grand No.81620108024.

\section{Availability of data and materials}

The datasets used and/or analyzed during the current study are available from the corresponding author on reasonable request.

\section{Authors' contributions}

$J L Z, C P$ and $X C$ developed the hypothesis, designed the experiments, and revised the manuscript. NL and KSW conducted experiments and wrote the main manuscript. YJZ and GYZ extracted and purified drugs. MQ, JT and JZ performed the statistical analyses. All authors read and approved the final manuscript.

\section{Ethics approval and consent to participate}

The animal protocol was approved by the Ethics Committee of Xiangya Hospital (Central South University, China).

\section{Consent for publication}

Not applicable.

\section{Competing interests}

The authors declare that they have no competing interests.

\section{Publisher's Note}

Springer Nature remains neutral with regard to jurisdictional claims in published maps and institutional affiliations. 


\section{Author details}

'Department of Dermatology, Xiangya Hospital, Central South University, Changsha, Hunan, China. ${ }^{2}$ Hunan Key Laboratory of Skin Cancer and Psoriasis, Changsha, Hunan, China. ${ }^{3}$ Department of Pathology, Xiangya Hospital, Central South University, Changsha, Hunan, China. ${ }^{4}$ Department of Pathology, School of Basic Medical Sciences, Central South University, Changsha, Hunan, China. ${ }^{5}$ Department of Plastic and Cosmetic Surgery, XiangYa Hospital, Central South University, Changsha, Hunan, China. ${ }^{6}$ School of Pharmaceutical Science,Central, South University, Changsha, Hunan, China. ${ }^{7}$ Department of Dermatology, Affiliated Union Hospital, Tongji Medical College, Huazhong University of Science and Technology, Wuhan, China. ${ }^{8}$ Department of Plastic Surgery of Third Xiangya Hospital, Central South University, Changsha, China.

\section{Received: 5 July 2018 Accepted: 31 August 2018}

\section{Published online: 06 November 2018}

\section{References}

1. Ferlay J, Soerjomataram I, Dikshit R, Eser S, Mathers C, Rebelo M, Parkin DM, Forman D, Bray F. Cancer incidence and mortality worldwide: sources, methods and major patterns in GLOBOCAN 2012. Int J Cancer. 2015;136(5): E359-86.

2. Ali Z, Yousaf N, Larkin J. Melanoma epidemiology, biology and prognosis. EJC Suppl. 2013;11(2):81-91.

3. Siegel RL, Miller KD, Jemal A. Cancer statistics, 2017. CA Cancer J Clin. 2017; 67(1):7-30.

4. Gray-Schopfer V, Wellbrock C, Marais R. Melanoma biology and new targeted therapy. Nature. 2007;445(7130):851-7.

5. Lo JA, Fisher DE. The melanoma revolution: from UV carcinogenesis to a new era in therapeutics. Science. 2014;346(6212):945-9.

6. Tsao H, Chin L, Garraway LA, Fisher DE. Melanoma: from mutations to medicine. Genes Dev. 2012;26(11):1131-55.

7. Fedorenko IV, Gibney GT, Smalley KS. NRAS mutant melanoma: biological behavior and future strategies for therapeutic management. Oncogene. 2013;32(25):3009-18.

8. Saranga-Perry V, Ambe C, Zager JS, Kudchadkar RR. Recent developments in the medical and surgical treatment of melanoma. CA Cancer J Clin. 2014; 64(3):171-85.

9. Kemper K, Krijgsman O, Kong X, Cornelissen-Steijger P, Shahrabi A, Weeber $F$, van der Velden DL, Bleijerveld $\mathrm{OB}$, Kuilman T, Kluin RJC, Sun C, Voest EE, Ju YS, Schumacher TNM, Altelaar AFM, McDermott U, Adams DJ, Blank CU, Haanen JB, Peeper DS. BRAF(V600E) kinase domain duplication identified in therapy-refractory melanoma patient-derived xenografts. Cell Rep. 2016; 16(1):263-77.

10. Wagle N, Van Allen EM, Treacy DJ, Frederick DT, Cooper ZA, Taylor-Weiner A, Rosenberg M, Goetz EM, Sullivan RJ, Farlow DN, Friedrich DC, Anderka K, Perrin D, Johannessen CM, McKenna A, Cibulskis K, Kryukov G, Hodis E, Lawrence DP, Fisher S, Getz G, Gabriel SB, Carter SL, Flaherty KT, Wargo JA, Garraway LA. MAP kinase pathway alterations in BRAF-mutant melanoma patients with acquired resistance to combined RAF/MEK inhibition. Cancer Discov. 2014;4(1):61-8.

11. Luke JJ, Flaherty KT, Ribas A, Long GV. Targeted agents and immunotherapies: optimizing outcomes in melanoma. Nat Rev Clin Oncol. 2017;14(8):463-82

12. Azimi A, Caramuta S, Seashore-Ludlow B, Bostrom J, Robinson JL, Edfors F, Tuominen R, Kemper K, Krijgsman O, Peeper DS, Nielsen J, Hansson J, Egyhazi Brage S, Altun M, Uhlen M, Maddalo G. Targeting CDK2 overcomes melanoma resistance against BRAF and Hsp90 inhibitors. Mol Syst Biol. 2018;14(3):e7858.

13. Zheng CJ, Li HQ, Ren SC, Xu CL, Rahman K, Qin LP, Sun YH. Phytochemical and pharmacological profile of Vitex negundo. Phytother Res. 2015;29(5): 633-47.

14. Zhou Y, Liu YE, Cao J, Zeng G, Shen C, Li Y, Zhou M, Chen Y, Pu W, Potters $L$, Shi YE. Vitexins, nature-derived lignan compounds, induce apoptosis and suppress tumor growth. Clin Cancer Res. 2009;15(16):5161-9.

15. Kadir FA, Kassim NM, Abdulla MA, Yehye WA. Hepatoprotective role of Ethanolic extract of Vitex negundo in Thioacetamide-induced liver fibrosis in male rats. Evid Based Complement Alternat Med. 2013;2013:739850.

16. Zheng CJ, Zhang XW, Han T, Jiang YP, Tang JY, Bromme D, Qin LP. Antiinflammatory and anti-osteoporotic lignans from Vitex negundo seeds. Fitoterapia. 2014;93:31-8
17. Kamruzzaman M, Bari SM, Faruque SM. In vitro and in vivo bactericidal activity of Vitex negundo leaf extract against diverse multidrug resistant enteric bacterial pathogens. Asian Pac J Trop Med. 2013;6(5):352-9.

18. Prasad E, Mopuri R, Islam M, Kodidhela L. Cardioprotective effect of Vitex negundo on isoproterenol-induced myocardial necrosis in wistar rats: a dual approach study. Biomed Pharmacother. 2017;85:601-10.

19. Wang JG, Zheng XX, Zeng GY, Zhou YJ, Yuan H. Purified vitexin compound 1 inhibits growth and angiogenesis through activation of FOXO3a by inactivation of Akt in hepatocellular carcinoma. Int J Mol Med. 2014;33(2):441-8.

20. Tan Z, Zhang Y, Deng J, Zeng G, Zhang Y. Purified vitexin compound 1 suppresses tumor growth and induces cell apoptosis in a mouse model of human choriocarcinoma. Int J Gynecol Cancer. 2012;22(3):360-6.

21. Xin H, Kong Y, Wang Y, Zhou Y, Zhu Y, Li D, Tan W. Lignans extracted from Vitex negundo possess cytotoxic activity by G2/M phase cell cycle arrest and apoptosis induction. Phytomedicine. 2013;20(7):640-7.

22. Bianchi-Smiraglia A, Bagati A, Fink EE, Moparthy S, Wawrzyniak JA, Marvin EK, Battaglia S, Jowdy P, Kolesnikova M, Foley CE, Berman AE, Kozlova NI, Lipchick BC, Paul-Rosner LM, Bshara W, Ackroyd JJ, Shewach DS, Nikiforov MA. Microphthalmia-associated transcription factor suppresses invasion by reducing intracellular GTP pools. Oncogene. 2017:36(1):84-96

23. Gorrini C, Harris IS, Mak TW. Modulation of oxidative stress as an anticancer strategy. Nat Rev Drug Discov. 2013;12(12):931-47.

24. Meek DW. Tumour suppression by p53: a role for the DNA damage response? Nat Rev Cancer. 2009;9(10):714-23.

25. Armata HL, Garlick DS, Sluss HK. The ataxia telangiectasia-mutated target site Ser18 is required for p53-mediated tumor suppression. Cancer Res. 2007;67(24):11696-703.

26. Xie J, Li Y, Jiang K, Hu K, Zhang S, Dong X, Dai X, Liu L, Zhang T, Yang K, Huang K, Chen J, Shi S, Zhang Y, Wu G, Xu S. CDK16 phosphorylates and degrades p53 to promote Radioresistance and predicts prognosis in lung Cancer. Theranostics. 2018:8(3):650-62.

27. Levine AJ. p53, the cellular gatekeeper for growth and division. Cell. 1997; 88(3):323-31.

28. Liu Z, Lu H, Shi H, Du Y, Yu J, Gu S, Chen X, Liu KJ, Hu CA. PUMA overexpression induces reactive oxygen species generation and proteasome-mediated stathmin degradation in colorectal cancer cells. Cancer Res. 2005;65(5):1647-54

29. Yang J, Zhao X, Tang M, Li L, Lei Y, Cheng P, Guo W, Zheng Y, Wang W, Luo N, Peng Y, Tong A, Wei Y, Nie C, Yuan Z. The role of ROS and subsequent DNA-damage response in PUMA-induced apoptosis of ovarian cancer cells. Oncotarget. 2017;8(14):23492-506.

30. Hu WL, Jin L, Xu A, Wang YF, Thorne RF, Zhang XD, Wu M. GUARDIN is a p53-responsive long non-coding RNA that is essential for genomic stability. Nat Cell Biol. 2018;20(4):492-502.

31. Ong ALC, Ramasamy TS. Role of Sirtuin1-p53 regulatory axis in aging, cancer and cellular reprogramming. Ageing Res Rev. 2018;43:64-80.

32. Elias J, Dimitrio L, Clairambault J, Natalini R. The p53 protein and its molecular network: modelling a missing link between DNA damage and cell fate. Biochim Biophys Acta. 2014;1844(1 Pt B):232-47.

33. Mollereau B, Ma D. The p53 control of apoptosis and proliferation: lessons from drosophila. Apoptosis. 2014;19(10):1421-9.

34. Lu M, Breyssens H, Salter V, Zhong S, Hu Y, Baer C, Ratnayaka I, Sullivan A, Brown NR, Endicott J, Knapp S, Kessler BM, Middleton MR, Siebold C, Jones EY, Sviderskaya EV, Cebon J, John T, Caballero OL, Goding CR, Lu X. Restoring p53 function in human melanoma cells by inhibiting MDM2 and cyclin B1/CDK1-phosphorylated nuclear iASPP. Cancer Cell. 2016;30(5):822-3.

35. Mazumdar T, Devecchio J, Agyeman A, Shi T, Houghton JA. Blocking hedgehog survival signaling at the level of the GLI genes induces DNA damage and extensive cell death in human colon carcinoma cells. Cancer Res. 2011:71(17):5904-14

36. Brown JS, O'Carrigan B, Jackson SP, Yap TA. Targeting DNA repair in Cancer: beyond PARP inhibitors. Cancer Discov. 2017;7(1):20-37.

37. Noh J, Kwon B, Han E, Park M, Yang W, Cho W, Yoo W, Khang G, Lee D. Amplification of oxidative stress by a dual stimuli-responsive hybrid drug enhances cancer cell death. Nat Commun. 2015;6:6907.

38. Raj L, Ide T, Gurkar AU, Foley M, Schenone M, Li X, Tolliday NJ, Golub TR, Carr SA, Shamji AF, Stern AM, Mandinova A, Schreiber SL, Lee SW. Selective killing of cancer cells by a small molecule targeting the stress response to ROS. Nature. 2011;475(7355):231-4. 
39. Wang L, Yu Y, Chow DC, Yan F, Hsu CC, Stossi F, Mancini MA, Palzkill T, Liao L, Zhou S, Xu J, Lonard DM, O'Malley BW. Characterization of a steroid receptor coactivator small molecule stimulator that overstimulates Cancer cells and leads to cell stress and death. Cancer Cell. 2015;28(2):240-52

40. Hang W, Yin ZX, Liu G, Zeng Q, Shen XF, Sun QH, Li DD, Jian YP, Zhang YH, Wang YS, Quan CS, Zhao RX, Li YL, Xu ZX. Piperlongumine and p53reactivator APR-246 selectively induce cell death in HNSCC by targeting GSTP1. Oncogene. 2018;37(25):3384-98.

41. Yang $Y$, Zhang $Y$, Wang L, Lee $S$. Levistolide a induces apoptosis via ROSmediated ER stress pathway in Colon Cancer cells. Cell Physiol Biochem. 2017:42(3):929-38

42. Colin DJ, Limagne E, Ragot K, Lizard G, Ghiringhelli F, Solary E, Chauffert B, Latruffe N, Delmas D. The role of reactive oxygen species and subsequent DNA-damage response in the emergence of resistance towards resveratrol in colon cancer models. Cell Death Dis. 2014:5:e1533.

43. Bonner WM, Redon CE, Dickey JS, Nakamura AJ, Sedelnikova OA, Solier S, Pommier Y. GammaH2AX and cancer. Nat Rev Cancer. 2008;8(12):957-67.

44. Xu HG, Zhai YX, Chen J, Lu Y, Wang JW, Quan CS, Zhao RX, Xiao X, He Q, Werle KD, Kim HG, Lopez R, Cui R, Liang J, Li YL, Xu ZX. LKB1 reduces ROS-mediated cell damage via activation of p38. Oncogene. 2015;34(29):3848-59.

45. Shi H, Hugo W, Kong X, Hong A, Koya RC, Moriceau G, Chodon T, Guo R, Johnson DB, Dahlman KB, Kelley MC, Kefford RF, Chmielowski B, Glaspy JA, Sosman JA, van Baren N, Long GV, Ribas A, Lo RS. Acquired resistance and clonal evolution in melanoma during BRAF inhibitor therapy. Cancer Discov. 2014;4(1):80-93.

46. Poulikakos Pl, Persaud Y, Janakiraman M, Kong X, Ng C, Moriceau G, Shi H, Atefi M, Titz B, Gabay MT, Salton M, Dahlman KB, Tadi M, Wargo JA, Flaherty KT, Kelley MC, Misteli T, Chapman PB, Sosman JA, Graeber TG, Ribas A, Lo RS, Rosen N, Solit DB. RAF inhibitor resistance is mediated by dimerization of aberrantly spliced BRAF(V600E). Nature. 2011:480(7377):387-90.

47. Zuo Q, Liu J, Huang L, Qin Y, Hawley T, Seo C, Merlino G, Yu Y. AXL/AKT axis mediated-resistance to BRAF inhibitor depends on PTEN status in melanoma. Oncogene. 2018;37(24):3275-89.

48. Girotti MR, Pedersen M, Sanchez-Laorden B, Viros A, Turajic S, NiculescuDuvaz D, Zambon A, Sinclair J, Hayes A, Gore M, Lorigan P, Springer C, Larkin J, Jorgensen C, Marais R. Inhibiting EGF receptor or SRC family kinase signaling overcomes BRAF inhibitor resistance in melanoma. Cancer Discov. 2013;3(2):158-67.

Ready to submit your research? Choose BMC and benefit from:

- fast, convenient online submission

- thorough peer review by experienced researchers in your field

- rapid publication on acceptance

- support for research data, including large and complex data types

- gold Open Access which fosters wider collaboration and increased citations

- maximum visibility for your research: over $100 \mathrm{M}$ website views per year

At BMC, research is always in progress.

Learn more biomedcentral.com/submissions 